\title{
Prevalence of Bedbugs Infestation, Crowding and Awareness Level Among Government Boarding Secondary School Students in Moshi Urban, Tanzania
}

Peter Raphael Massawe ( $\nabla$ massawepeter124@gmail.com )

Kilimanjaro Christian Medical University College

Ezekiel Emmanuel Wahhay

Kilimanjaro Christian Medical University College

Baraka Gideon

Kilimanjaro Christian Medical University College

JOVIN KITAU

Kilimanjaro Christian Medical University College

Amedeus Mushi

Singida Regional Referral Hospital

\section{Research}

Keywords: bedbug infestation, awareness, crowding

Posted Date: July 24th, 2020

DOI: https://doi.org/10.21203/rs.3.rs-47433/v1

License: (c) (1) This work is licensed under a Creative Commons Attribution 4.0 International License.

Read Full License 


\section{Abstract}

Background. Bedbug infestation is the worldwide problem according to World Health Organization, and the infestation is characterized by biting reactions including systemic, cutaneous reactions and sometimes psychological disturbance. Prevalence of bedbug infestation is low (6\%) in developed countries while in Sierra Leone is $98 \%$ and Tanzania is $56 \%$ in which is tremendously high. As the bedbug infestation is among neglected conditions and because of high prevalence in Tanzania, the studies to determine this burden, some risk factors (crowding) and awareness among specific populated communities especially schools is inevitable for planning strategies in eradication of bedbug.

Objective. To determine the prevalence of bedbug infestation, crowding and awareness level among boarding government secondary school students in Moshi Urban.

Methodology. A cross-sectional study was conducted from May to July 2018 at Moshi Urban in Kilimanjaro region. The structured standard questionnaire was used to obtain the demographics information of participants, asses awareness. Personal observation was used to determine prevalence and crowding in the corresponding student's dormitories.

Results. The prevalence of bedbug infestation was 58.1\% (223) among 384 study participants. Logistic regression analysis showed that $72.6 \%$ of the students with bedbug infestation were found to be living in the overcrowded dormitories. There was association between overcrowd and bedbug infestation $(\mathrm{OR}=2.50,95 \% \mathrm{Cl}(1.63-3.83)$. Only $32.7 \%$ of the infested students involved in this study were aware with bedbugs $(\mathrm{OR}=0.8795 \% \mathrm{Cl}(0.56-1.35) \mathrm{P}=0.54$.

Conclusion. The overall prevalence of bedbug infestation was found to be high among students living in the overcrowded dormitories and those who were not aware on bedbug biology and behavior, transmission, control and prevention ways. Education concerning bedbugs is needed to increase the community awareness together with management of number of student in accordance to the available facilities and resources.

\section{Background}

Bedbug infestation is a worldwide problem; according to World Health Organization (WHO) overcrowded communities are mostly vulnerable ${ }^{(1,2)}$.

Bedbugs are hematophageous arthropods of class Insecta order Hemiptera and family Cimicidae, they have mouthparts which are capable of piercing the skin releasing saliva which contains anti-coagulants and vasodilators ${ }^{(3)}$. Bedbugs are wingless with elongated body and six-legs that require nourishment from the human blood and other small animals ${ }^{(2,3)}$. Two common species are associated with human infestation, Cimex lectularis and Cimex hemipterus. Cimex lectularis is cosmopolitan while Cimex 
hemipterus is found in tropical regions ${ }^{(1,2)}$. Bedbugs prefer to hide in the dark areas and they usually appear at night, the favorite area to isolate bedbugs are cracks, beddings and within the furniture frames $^{(5)}$.

United States, Canada, Europe, Central Asia and Africa have recently reported resurgence of bedbugs $(1,2)$. National Pest Management Association (NPMA) and WHO suggested the world and developed countries are on the verge of bedbug pandemic ${ }^{(7)}$. According to WHO the increased infestation was the result of the increased international travel, the ban of some insecticides like DDT, and increased resistance of bedbugs to insecticides ${ }^{(2)}$. Studies across United State (US) have pointed highly populated areas and low income communities are vulnerable to infestation ${ }^{(8-10)}$. In rural settlements of Benue state Nigeria among 199 residential apartments, which were surveyed 1056 bedbugs were collected from 26 apartments while other apartments showed probable infestation and some did not show any signs of infestation ${ }^{(12)}$. There is reported infestation in Freetown, Sierra Leone in which 238 rooms were searched during the day and night ${ }^{(13)}$. In Tanzania study conducted in Matimbwa and Kongo villages in Bagamoyo district found 61 houses infested among 108 houses inspected houses ${ }^{(14)}$. The study in Bagamoyo was among the studies conducted in Tanzania on bedbug insecticide side susceptibility ${ }^{(14-16)}$, while there is no published study specifically determining prevalence of bedbug infestation.

Health impacts of bedbug infestation include bedbug bite reactions, psychological effects of bedbug attack and bedbugs as the vector of human disease ${ }^{(3,18)}$. Bite reactions and psychological effects of bedbug infestation are experimentally and theoretically investigated while there is little evidence that bedbugs act as vectors of human disease ${ }^{(3,20)}$. Skin of the arm, legs, trunk, neck, hands and face are the vulnerable areas for the bedbug biting reactions, the reactions from bedbug bite can be cutaneous or systemic $(3,9,20)$. Cutaneous bite reactions are characterized by itching or abraded $2-5 \mathrm{~mm}$ pruritic maculopapular and erythematous lesions at bedbug feeding sites ${ }^{(20)}$.

Despite several studies on bedbug insecticide susceptibility, in Tanzania bedbug infestation is expected to be increasing due to increase in resistant strains ${ }^{(14-16)}$.

Since the infestation is more likely in overcrowded areas, especially the boarding schools are on the high risk of infestation because are coming from different region and families. This study determines the prevalence of bedbug infested beds, which was considered as the prevalence of infestation among students.

\section{Methodology}

\section{Study Design}

This was a cross-sectional study design conducted from May to July 2018 among secondary school students in Kilimanjaro region. 


\section{Study area}

The study was carried in government boarding secondary schools which are Moshi Urban in Kilimanjaro region

\section{Study Population}

The study population was 384 students in three government boarding secondary schools in Moshi urban.

\section{Inclusion criteria}

Registered students in boarding government schools at Moshi Urban

Students willing to participate in the study

\section{Exclusion criteria}

Students with visual disorders

\section{Sample Size and Sampling Techniques}

Convenient sampling technique was used in selection of three government boarding secondary schools located in Moshi Urban. Systematic random selection of students was applied to obtain the number of students who participated in the study for each school.

\section{Variables}

\section{Dependent variable}

Bedbug infestation

\section{Independent variables}

Crowding level, awareness, students' family residence, sex and age

\section{Data Collection Tools and Methods}


Questionnaires were the tools used for data collection, used to obtain social demographics information of the participants which were age, sex, and family residence. The observation checklist was used to assess the bedbug eggs and feaces from student's dormitory beds.

\section{Data Analysis}

Data were entered, cleaned, and analyzed by using Statistical Package for Social Science (SPSS) Version 20. Descriptive statistics was used to summarize data where in categorical data percentage and proportion was used to summarize data. Frequency tables and figures bar graph was used in data presentation and interpretation.

\section{Results}

Out of 384 participants $54.9 \%$ aged 18 and above years which was relatively higher compared to those aged below 18 years (45.1\%). Regarding class category $51.3 \%$ of the participants were in advanced level. To maintain confidentiality participating schools will from this point be referred using letters $\mathrm{X}, \mathrm{Y}$ and $\mathrm{Z}$. Of all participating students $34.4 \%$ were from $X$ while $33.9 \%$ and $31.8 \%$ were from $Y$ and $Z$ respectively. Among the study participants boys constituted $53.1 \%$ while $53.9 \%$ of all students were from urban and $46.1 \%$ were from rural areas. 
Table 1

Socio-demographic characteristics of participants $(\mathrm{N}=384)$.

\begin{tabular}{|lll|}
\hline Variables & N & $\%$ \\
\hline Age group (years) & & \\
\hline 18 and above & 211 & 54.9 \\
\hline Below 18 & 173 & 45.1 \\
\hline School name(secondary) & & \\
\hline Z & 122 & 31.8 \\
\hline Y & 130 & 33.9 \\
\hline X & 132 & 34.4 \\
\hline Sex & & \\
\hline Male & 204 & 53.1 \\
\hline Female & 180 & 46.9 \\
\hline Family residence & & \\
\hline Urban & 207 & 53.9 \\
\hline Rural & 177 & 46.1 \\
\hline Class category & & \\
\hline O-level & 187 & 48.7 \\
\hline A-level & 197 & 51.3 \\
\hline
\end{tabular}

The overall prevalence of bedbug infestation was $58.1 \%$. School-wise prevalence was $72.3 \%$ in school $Y$, $64.4 \%$ in school $X$ and $36.1 \%$ in school Z. Y school had higher proportion in the overall prevalence $(24.5 \%)$ followed by school X (22.2\%) while school Z contributed the least (11.5\%). The Table 2 below summarizes prevalence of bedbug infestation in the respective schools.

Table 2

Prevalence of bedbug infestation by school $(\mathrm{N}=384)$

\begin{tabular}{|llll|}
\hline \multicolumn{4}{|c|}{ Infestation status $\mathbf{n}(\%)$} \\
\hline School name & Infested & Not infested & Total \\
\hline Y & $94(72.6)$ & $36(27.7)$ & $130(100)$ \\
X & $85(64.4)$ & $47(35.6)$ & $132(100)$ \\
\hline Z & $44(36.1)$ & $78(63.9)$ & $122(100)$ \\
\hline
\end{tabular}


Out of 223 students who were found to have been infested $59.6 \%$ were boys, $52.5 \%$ were advanced level students (form V\&VI), 55.6\% were aged above 18 years and $44.4 \%$ aged below 18 years. In addition, among students who were infested with bedbugs $50.2 \%$ were from rural while $49.8 \%$ were from urban areas. Majority of infested students were found to have other signs of bedbug infestation.

Table 3

Social-demographic characteristics of bedbug infested students $(\mathrm{N}=223)$

\begin{tabular}{|lll|}
\hline Variable & Frequency & Percentage \\
\hline Age & & \\
\hline Below 18 & 99 & 44.4 \\
\hline 18 and above & 124 & 55.6 \\
\hline Sex & & \\
\hline Male & 133 & 59.6 \\
\hline Female & 90 & 40.4 \\
Residence & & \\
\hline Rural & 112 & 50.2 \\
\hline Urban & 111 & 49.8 \\
\hline Bedbug stage & & \\
\hline Adult & 98 & 43.9 \\
\hline Other sign & 125 & 56.1 \\
\hline
\end{tabular}

Most of the students were found to be living in overcrowded dormitories, $63.8 \%$ of inspected students were living in dormitories which students outnumbered the beds. Overall number of boarding students and the corresponding number of beds in the respective schools were 1240 and 1220 in Y school, 790 and 760 in X school and 423 and 421 in Z school. Among 223 students who had bedbug infestation those living in overcrowded dormitories had a higher infestation rate $(72.6 \%)$. Univariate logistic regression showed there was statistically significant difference in the prevalence of bedbug infestation between the students living in the overcrowded dormitories compared to those living in non-crowded dormitories $(p<0.05)$. 
Table 4

Univariate logistic regression of association between crowding and bedbug infestation $(\mathrm{N}=384)$

\begin{tabular}{|lllll|}
\hline Variable & $\begin{array}{l}\text { Infestation } \\
\text { N (\%) }\end{array}$ & cOR & -value \\
\hline & Yes & No & & \\
\hline Crowded & $162(72.6)$ & $83(51.6)$ & $2.50(1.63-3.83)$ & 0.001 \\
\hline Not crowded & $61(27.4)$ & $78(48.4)$ & 1 & \\
\hline
\end{tabular}

Of the 384 students who participated in the study only $31.5 \%$ were aware of the bedbug biology, transmission and control methods while the remaining students had limited awareness. About $92 \%$ of all participants were aware on bedbug biology, $47.4 \%$ were aware of methods involved in bedbug transmission and $70.3 \%$ were aware of control and prevention of bedbugs. Environmental cleanness was the most bedbug prevention method mentioned by $36.2 \%$ of the participating students; other methods familiar to the students were reduce crowding in dormitories (17.2\%), sun-heating of beddings (13.3\%), use of hot water (9.4\%), use of iron beds (4.4\%), freezing beddings ( $2.3 \%)$, education (2.1\%), use of dried clothes $(1.8 \%)$ while $13.3 \%$ of the students were not aware of any bedbug prevention or control method.

Univariate logistic regression result showed that students with limited or those who were not aware about bedbugs had higher prevalence of infestation (67.3\%). However, there was no statistically significant association between prevalence of infestation and general awareness among students. Also, $93.7 \%$ of infested students were found to be aware about bedbug biology and behavior, however, the association was found to be statistically not significant, $48.4 \%$ of infested students were aware of bedbugs transmission methods, the association was also statistically not significant $(P=0.63)$. The prevalence of bedbug infestation among students who were aware of bedbug prevention and control methods were $71.7 \%$, the association was statistically not significant $(P>0.05)$. 
Table 5

Univariate logistic regression of association between awareness level and bedbug infestation $(\mathrm{N}=223)$

\begin{tabular}{|lllll|}
\hline Variable & \multicolumn{2}{l}{ Bedbug infestation $n(\%)$} & cOR & p-value \\
\hline Yes & No & & \\
\hline Aware & & & & \\
\hline Not aware & $73(32.7)$ & $48(29.8)$ & $0.87(0.56-1.35)$ & 0.54 \\
\hline Bedbug biology & $150(67.3)$ & $113(70.2)$ & 1 & \\
\hline Aware & & & & 0.37 \\
\hline Not aware & $209(93.7)$ & $14(8.7)$ & $0.70(0.32-1.52)$ & 0.63 \\
\hline Bedbug transmission ways & & $147(91.3)$ & 1 & \\
\hline Aware & $14(6.3)$ & & & \\
\hline Not aware & $108(48.4)$ & $74(46.0)$ & $0.90(0.60-1.36)$ & 0.63 \\
\hline Bedbug control \& prevention & & $87(54.0)$ & 1 & \\
\hline Aware & $115(51.6)$ & & & \\
\hline Not aware & $160(71.7)$ & $110(68.3)$ & $0.85(0.54-1.32)$ & 0.47 \\
\hline
\end{tabular}

\section{Discussion}

The overall infestation rate among secondary school students was $58.1 \%$. this was nearly the same of study conducted in Bagamoyo Tanzania which was $56.5 \%{ }^{(14)}$. The prevalence was much higher compared to that found in New York City $(6.6 \%)$ and $21.8 \%$ in Nigeria ${ }^{(12)}$

The students were coming from North- Eastern Zone were more affected by bedbugs this was similar to the previously community study reported in Manyara and Tanga which are northern region in Tanzania ${ }^{(15}$, 16). Therefore the students coming from family with bedbug infestation might have carried bedbugs from their home to school and spread among themselves at higher rate.

The findings of the study also indicate that students from the rural setting had higher chance of being infested, though the difference of infestation is small because among study participants, students from urban setting had high proportion.

The prevalence of bedbug infestation among students living in overcrowded dormitories was $72.6 \%$. Association between bedbug infestation and crowding level in the community has been reported in the previous studies suggesting that poverty and crowding are predicting factors of bedbug infestation ${ }^{(21)}$. 
The findings of this study show that bedbug infestation is high among students living in overcrowded (high number of students per number of beds) dormitories. Also because students have the tendency of sharing beds and mattresses, the increased interaction between students living in the same dormitory could also be significant in bedbug transmission. Many student dormitories were old and with old designs because the student beds were nearly placed, the pattern which was suggested to be the risk factor for the spread of bedbugs ${ }^{(6,10)}$.

The overall awareness among students with bedbug infestation was about $32.7 \%$. Study done by Geraldo reported nearly similar results in which $30 \%$ of participants were able to correctly identify bedbugs (22), this highlights the fact that people who are less aware about bedbugs are prone to bedbug infestation. Poor awareness among students leads to delay of information to the responsible authorities hence increase in bedbug infestation rate.

\section{Conclusion}

The results of this study high prevalence of bedbug in government boarding secondary schools which was associated with overcrowding of the students in the dormitories. There was limited awareness of bedbug infestation for some secondary school students. The forums and prevention programs should focus on educating people so that to increase the community awareness about bedbugs. Also the fumigation should be done in dormitories during students entry soon after vacation.

\section{Abbreviations}

Cl: Confidence interval,

cOR: crude odds ratio

\section{Declarations}

\section{Author Contributions}

PRM, EEW and BG for design, data collection, data analysis and manuscript writing;

JK and ALM contributed in reviewing the manuscript for intellectual content.

\section{Declaration of Conflicting Interests}

The authors declare no potential conflicts of interest with respect to the research, authorship and publication of this article.

\section{Acknowledgments}


The authors would like to thank all government boarding secondary school student from Moshi urban who participated in the study.

\section{Funding}

No fund granted for this study.

\section{Ethical Approval}

Ethical approval was granted from the Kilimanjaro Christian Medical University College Research Ethics Committee. The permission to conduct this study was obtained from the Moshi Municipal Director, Moshi Municipal secondary schools education officer and school administration.

\section{Informed Consent}

Written informed consent was obtained from the participants.

\section{References}

1. CDC. Centres for Disease Control and Prevention \& U.S Disease Protection Agency (2010).

2. Organization WH, Office R. Public health significance of urban pests. 2008.

3. Goddard J, Lectularius I, Been HAS. CLINICIAN' S CORNER Bed Bugs ( Cimex lectularius ) and Clinical Consequences of Their Bites. 2015;301(13).

4. Murrell DF. Benjamin S. Daniel, BA, BCom, MBBS Dedee F. Murrell, BMBCh, MD, FACD. 2013;149(3):372-3.

5. Chen H, Copes R. A review on bed bugs: epidemiology, health effects, and surveillance activities. 2010;(November).

6. Hong T, Es M, Abdalhamid B, Wang J, Sloan C, Gupta J, et al. Bedbugs and associated Dermatitis , France. 2009;15(6):989-90.

7. NPMA. National Pest Mangement Association. (2011). The bedbug Hub. 2011.

8. Gounder P, Ralph N, Maroko A, Thorpe L. Bedbug Complaints among Public Housing Residents New York City , 2010 - 2011. 2014;2010-1.

9. Kaylor MB. Prevalence, Knowledge, and Concern about Bed Bugs. 2011;

10. Wang C, Singh N, Zha C, Cooper R. Vector Control, Pest Management, Resistance, Repellents Bed Bugs: Prevalence in Low-Income Communities, Resident's Reactions, and Implementation of a Low-Cost Inspection Protocol. 2016;53(April):639-46.

11. Gounder P, Ralph N, Maroko A, Thorpe L. Bedbug Complaints among Public Housing Residents-New York City, 2010-2011. J Urban Heal. 2014;91(6):1076-86. 
12. Omudu EA, Kuse CN. Bedbug infestation and its control practices in Gbajimba: a rural settlement in Benue state, Nigeria. 2010;(December):222-7.

13. A. A Gbakima, B. C TERRY, F. KANJA, S. KORTEQUEE IDAFS. prevalence of bedbug infestation in sieraleone.pdf. 2002.

14. E.A. TEMU, J.N. MINJAS CJS and AM. Bedbug control by permethrin-impregnated bednets in Tanzania. Med Vet Entomol. 1999;13:457-9.

15. J. MYAMBA, C.A.MAXWELLy AA y and CFC. Pyrethroid resistance in tropical bedbugs , Cimex hemipterus, associated with use of treated bednets. Med Vet Entomol. 2002;16:448-51.

16. Kweka EJ, Mwang'onde BJ, Kimaro EE, Msangi S, Tenu F, Mahande AM. Insecticides Susceptibility Status of the Bedbugs (Cimex lectularius) in a Rural Area of Magugu, Northern Tanzania. J Glob Infect Dis. 2009;1(2):102-6.

17. Curtis $C F$, Jana-kara B, Maxwell CA. Insecticide treated nets: impact on vector populations and relevance of initial intensity of transmission and pyrethroid resistance. 2003;(June):1-8.

18. Ashcroft R, Seko Y, Fong L, Jessica C, Kim J, Mckenzie K. The mental health impact of bed bug infestations: a scoping review. Int J Public Health. Springer Basel; 2015;

19. Goddard J, De Shazo R. Psychological effects of bed bug attacks (Cimex lectularius L.). Am J Med. Elsevier Inc.; 2012;125(1):101-3.

20. Mcmenaman KS, Gausche-hill M. Recognition , Management, and Eradication Cimex lectularius ( “ Bed Bugs" ). 2016;32(11):801-4.

21. Giorda F, Guardone L, Mancini M, Accorsi A, Macchioni F, Mignone W. in Northwest Italy. 2013;33540.

22. Gerardo EM, Spafford H, Yates J. Increasing awareness of and education about bed bugs (. 2014; (May). 